\title{
AUTOMATED WASTE SEGREGATOR
}

\author{
Ravindra M. Gimonkar \\ Associate Professor, Dept. of Electrical Engineering \\ Yeshwantrao Chavan College of Engineering, Nagpur, India \\ Email: \{r.gimonkar@rediffmail.com\}
}

\begin{abstract}
In the modern world, there is a continuous increasing capacity for various categories of solid waste. Waste has become the biggest problem in today's world. Until now there is no proper management of waste. For managing the waste there are various segregation methods and products available but only at industrial levels. To properly pull off the waste it has to be handled, separate, transported and disposed of so as to reduce the risks to the public lives and sustainable environment. The economic value of waste is best comprehended when it is sequestered. This paper aims towards an automatic waste segregation system at the household level and small society peoples. This system is easy and has a simple solution to segregating the waste into three categories of metal waste, solid waste, and wet waste. Here we are using Arduino Uno for segregation operation. For each waste we use an electronic sensor for detection and for separation small mechanical arms are used. This paper will help society with waste management and aims to recycle the waste accordingly.
\end{abstract}

\section{Keywords-Automation, industrial management, segregation}

\section{Introduction}

By referring Press Information Bureau, India generates 62 million tonnes of waste (mixed waste containing both recyclable and non- recyclable waste) every year, with an average annual growth rate of $4 \%$ (PIB 2016). The generation and disposal of waste in large amounts have created great concern overtime for the world which is adversely affecting human lives and environmental conditions. In fact, waste is the ones that grow with the growth of the country. In the modern world, people are adapted to tossing out waste without knowing its adverse effe $4 \mathrm{ct}$ on the environment. The common method for disposal of waste at the industrial level is uncontrolled and unplanned it involves dumping of waste into open fields, landfills, or into the water body.

Thus, affecting the environment and animals. So a segregation method must be set up for proper disposal of waste in modern society in an environment safety mode means it should be done in such a way that it doesn't affect the environment and beings living in it. Also, a proper waste segregation method can bring out the economic value of waste thus contributing to the economy of the country. The recent advancements in technology have made waste a crucial thing as the conversion of waste into different forms can be used in many ways like with organic waste. We can use it to harness biogas energy, also organic waste also known as biomass can be used for the creation of ethanol, recyclable waste such as plastic can be recycled and reused further thus decreasing the waste quantity, metallic waste could be reused or recycled. A system was developed that can segregate the waste according to its nature like metallic waste, dry waste, and wet or moisture containing waste at household or small society level. Even though there is large-scale industrial waste separation present, it is always much better to separate the waste at the source itself. The benefits of doing so are that a higher quality of the material is preserved for recycling which means that more value can be recovered from the waste. Also, the occupational hazard for waste workers is reduced. After segregation segregated waste can directly be sent to recycling and processing plants instead of sending it to the segregation plant than a recycling plant.

\section{Methodology}

\section{A. System Design}

Firstly waste is pushed onto a conveyor belt. The conveyor motor starts to rotate then the waste is combine and detected by IR and Inductive Proximity Sensor. The purpose of IR sensor is to check whether the waste is present or not, and inductive proximity sensor checks whether the waste is metallic or not. In this case if both the conditions of the sensor is correct then the conveyor stops and the moving arm 1 slides the waste into bin 1 if not then the conveyor belt keeps on moving. If the waste is nonmetallic then the conveyor keeps on rotating further it is detected combine by IR \& Moisture Sensor Here purpose of the IR sensor is to check the presence of waste and the moisture sensor detects the presence of moisture in the waste. 


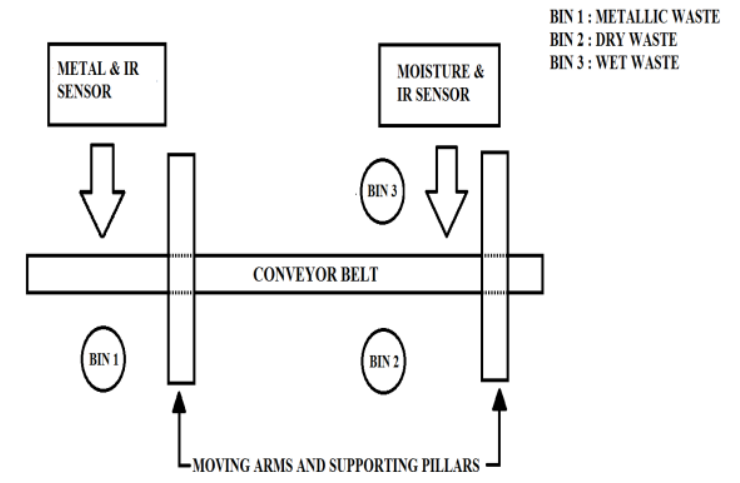

Fig 1: Block diagram of proposed work
If both the conditions of the sensor are true then the waste is classified as wet if the condition of the moisture sensor is false then the waste is classified as dry. If waste is categorized as wet then the moving arm 2 pushes the waste in bin 2 otherwise if waste is dry then the moving arm 2 pushes the waste in bin 3.Hence the waste is segregated. In this process the LCD keeps us showing the type of garbage collection and the motor accompanied in the process of segregation, further appropriate voltage is given to the circuit which helps in the proper functioning of the micro-controller ATMEGA 32 circuit along with the complete system.

Table 1: Sensor status according to type of waste

\begin{tabular}{|l|l|l|l|l|}
\hline Types of Waste & Metal Sensor & Infrared Sensor 1 & Moisture Sensor & Infrared Sensor 2 \\
\hline Metal & True & True & - & - \\
\hline Wet & - & - & True & True \\
\hline Dry & - & - & False & False \\
\hline
\end{tabular}

\section{B. Development of Sensing Part}

In the sensing part, the sensing circuit is constructed using infrared sensor (IR sensor), inductive proximity sensor and moisture sensor as shown in Fig 1. Each sensor has a different function in order to distinguish the different types of waste.
Based on Table 2 the infrared sensor is used to check whether the waste is detected or not, the inductive proximity sensor is used to detect the presence of metal, and the moisture sensor is used to detect the presence of moisture in the waste.

Table 2: List of Sensors

\begin{tabular}{|l|l|}
\hline \multicolumn{1}{|c|}{ Type of Sensor } & Type of Detection \\
\hline Infrared (IR) Sensor & Existence of object \\
\hline Inductive Proximity Sensor & Magnetic Field \\
\hline Moisture Sensor & Electrical Conductivity \\
\hline
\end{tabular}

\section{Development of Mechanical Part}

The mechanism of rotating the waste separation part and dropping the waste into the correct partition of the bin is the mechanical part of the project. This, part consists of one dc motor, two servo motors, and three sorting openings with compartments for metallic, dry, and wet waste. The motors used for this project, their purpose, and the location are listed in Table 3. 
Table 3: List of Motors

\begin{tabular}{|c|c|}
\hline Type Of Motor & Purpose of motor \\
\hline DC motor & For rotating the conveyor belt \\
\hline Servo motor 1 & $\begin{array}{c}\text { For pushing the waste into } \\
\text { metallic bin }\end{array}$ \\
\hline Servo motor 2 & $\begin{array}{c}\text { For pushing the waste into dry } \\
\text { and waste bin }\end{array}$ \\
\hline
\end{tabular}

In addition, the body of the waste separator prototype is made of various types of materials. The base of the prototype is made of acrylic plastic also the flaps of mechanical arms are made of acrylic sheets. The supports for the servo motor and in which it is attached is by astral PVC pipes.Mechanical support to prototype is given by sets of L supports and acrylic sheets of greater thickness.

\section{Development of Programming Part}

In order to instruct the sensors and mechanical parts to perform the specific task, the programming part is required for the Arduino. For this work, only basic embedded $\mathrm{C}$ programming is used.It is used to declare the pins to connect to the input and output components. On the other hand, the library of components that have been used also needs to be included.This library contains the function of embedded $\mathrm{C}$ standard input and output. In addition, the algorithm used is an 'if-else' statement.This statement is used for decision making and based on the decision the next block of code is executed. Fig 2 shows the flowchart of coding of automated waste separator and its operation.For example, the servo motor is rotated based on the different signals that are received from two different sensors at the same time. If an IR sensor detects an object and at the same time if object is containing some metallic components like aluminum and it is sensed by an inductive proximity sensor the servo will decide to move to $90^{\circ}$ based on decision made and will return to its normal position as stated in the program.

\section{Results and discussions}

In order to instruct the sensors and mechanical parts to perform the specific task, the programming part is required for the Arduino. For this work, only basic embedded $\mathrm{C}$ programming is used.It is used to declare the pins to connect to the input and output components. On the other hand, the library of components that have been used also needs to be included. This library contains the function of embedded $\mathrm{C}$ standard input and output.In addition, the algorithm used is an 'ifelse' statement. This statement is used for decision making and based on the decision the next block of code is executed. Fig 2 shows the flowchart of coding of automated waste separator and its operation. For example, the servo motor is rotated based on the different signals that are received from two different sensors at the same time. If an IR sensor detects an object and at the same time if object is containing some metallic components like aluminum and it is sensed by an inductive proximity sensor the servo will decide to move to $90^{\circ}$ based on the decision made and will return to its normal position as stated in the program. 


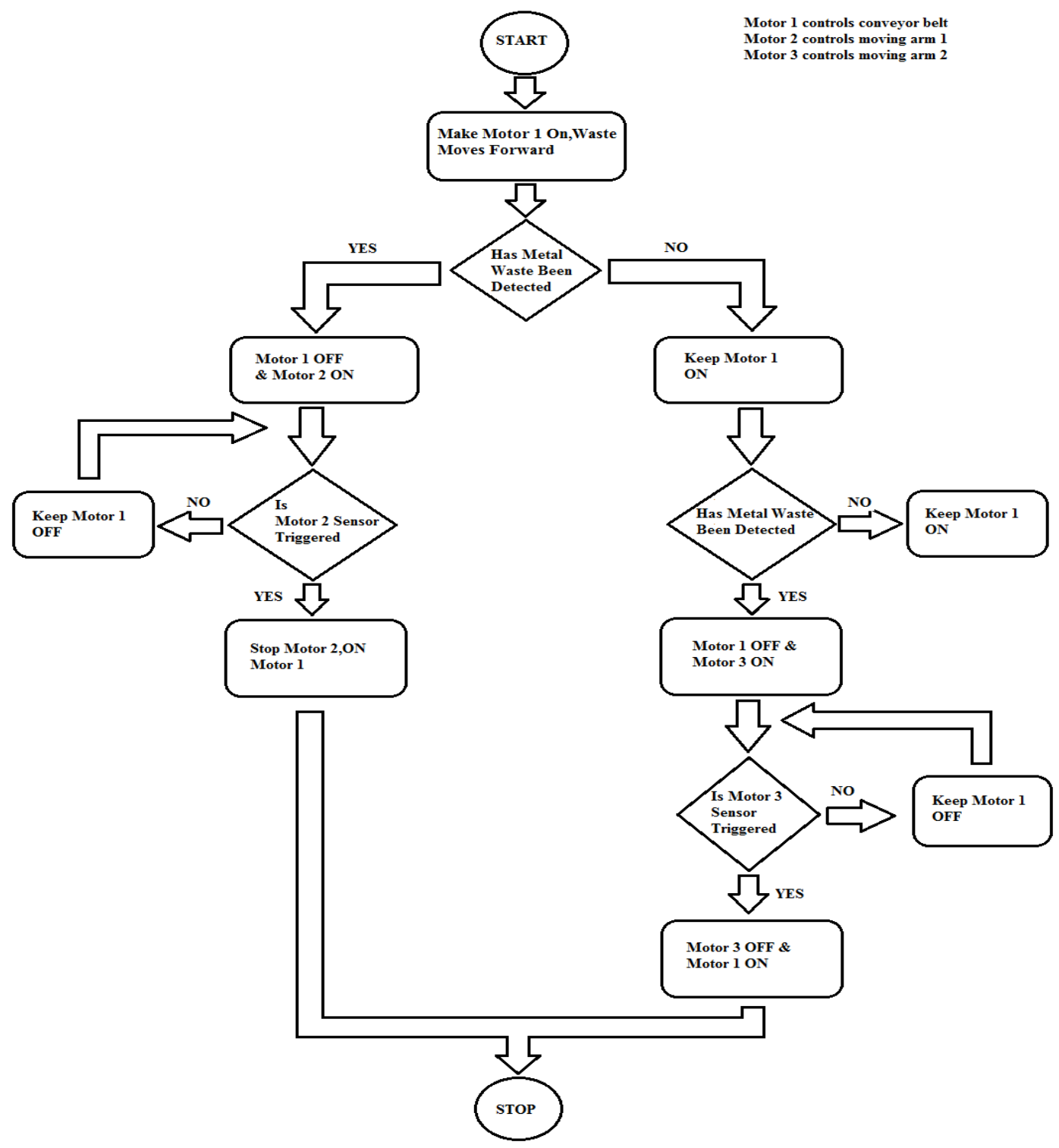

Fig 2: Flowchart of the Program

Table 4. Results of waste material tested

\begin{tabular}{|c|c|c|c|c|}
\hline Waste Tested & True Acceptance & True Rejection & False Acceptance & False Rejection \\
\hline Metallic & 8 & 6 & 2 & 4 \\
\hline Dry & 7 & 5 & 3 & 5 \\
\hline Wet & 7 & 4 & 3 & 6 \\
\hline
\end{tabular}




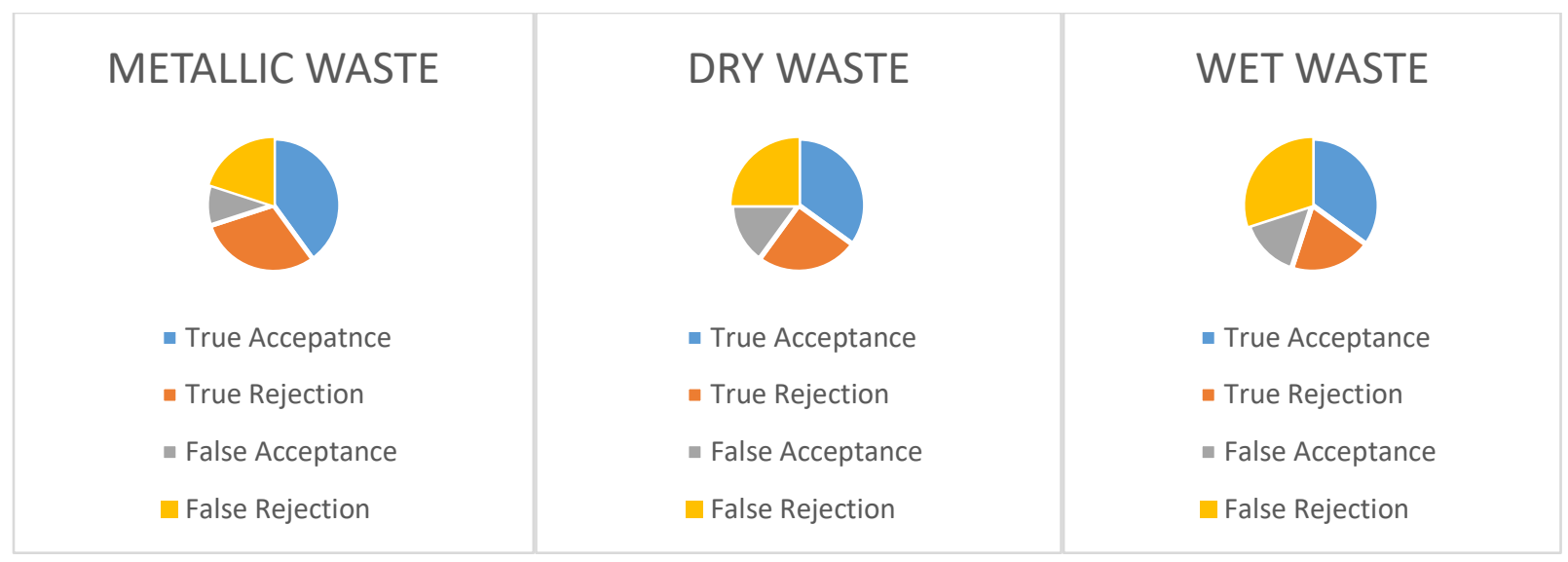

Figure 3. Types of waste

\section{Conclusion}

In this paper, the development of a lowcost automated waste separator powered by Arduino micro-controller is presented to effectively sort waste according to its base at the household or small society level. During the development process, the waste separator prototype control system and sensing mechanism are integrated using an Arduino Uno microcontroller. The sensing part is built to distinguish among three types of waste: 1) metallic waste, 2) dry waste and 3) wet waste. The metallic waste utilized the inductive proximity sensor in relation to the magnetic field concept. However dry and wet waste used moisture sensors to verify electrical conductivity. The prototype of the waste separator possessed high sensitivity on metallic waste in comparison to other waste. This means that dry and wet waste sensitivity needs to be improved for effective sorting. The proposed concept and developed prototype have the potential to be utilized in reducing the cost of solid waste disposal in the future.

\section{References}

[1] M. K. Pushpa, Aayushi Gupta, Shariq Mohammed Shaikh, Stuti Jha,Suchitra.V, "Microcontroller Based Automatic Waste Segregator",International journal of innovative research in Electrical, Electronics, Instrumentation and Control Engineering Vol. 3, issue 5, May 2015.

[2] Amrutha Chandramohan, Joyal Mendonca, Nikhil Ravi Shankar, Nikhil U Baheti, Nitin Kumar Krishnan, Suma M S, Rashtreeya Vidyalaya College of Engineering (R.V.C.E.) "Automated Waste Segregator
[3] Abhay Bharadwaj, Rainer Rego, Anirban Chowdhary, "IOT based solid waste management system", IEEE Annual India Conference (INDICON), 2016.

[4] P. Ash, Bist, A., and Chandran.S, S., "Moving towards Zero-Waste: A

Case-Study from Kerala, India”, IEEE Global Humanitarian Technology,Conference,SouthAsia Satellite Conference, Trivandrum, India, 2013.

[5] Subhasini Dwivedi, Michael Fernandes, Rohit Dsouza, A Review on PLC based Automatic Waste Segregator, International Journal of Advanced Research in Computer Engineering and Technology (IJARCET) Volume 5 Issue 2, February 2016

[6] Fachmin Folianto, Yong Low, Wai Yeow, "Smartbin smart waste management system", IEEE International Conference on Intelligent Sensors Sensors Network and Information Processing (ISSNIP), 2015J.

[7] Clerk Maxwell, A Treatise on Electricity and Magnetism, 3rd ed., vol. 2. Oxford: Clarendon, 1892, pp.68-73.

[8] S. Sakai, S. Sawell, A. Chandler, "World Trend in Municipal Solid Waste Management" in Environmental Preservation Center, Japan, vol. 16, pp. 341, 1996.

[9] "Smart Garbage Monitoring and Clearance System using Internet of Things", 2017 IEEE International Conference on Smart Technologies and Management for Computing Communication Controls Energy and Materials (ICSTM), 2 - 4 August 2017.

[10] Mahmudul Hasan Russel, Mehdi Hasan Chowdhury, Md. Shekh Nairn Uddin, Ashif Newaz, Md. Mehdi Masud Talukder, "Development of Automatic Smart Waste Sorter Machine", International Conference on Mechanical Industrial and Materials Engineering 2013 (ICMIME2013), 1-3 November, 2013. 